\title{
The Satellite Insurance Market and Underwriting Cycles
}

\author{
Piotr Manikowski ${ }^{\mathrm{a}}$ and Mary A. Weiss ${ }^{\mathrm{b}}$ \\ ${ }^{a}$ Insurance Department, Poznań University of Economics, al. Niepodległości 10, Poznań 61-875, Poland. \\ E-mail: piotr.manikowski@ue.poznan.pl \\ ${ }^{b}$ Risk, Insurance, \& Healthcare Management Department, Temple University, Alter Hall, Room 624, 1801 \\ Liacouras Walk, Philadelphia, PA 19122, U.S.A. \\ E-mail: mary.weiss@temple.edu
}

This research analyses whether underwriting cycles are present in an important but often overlooked line of insurance, satellite insurance. Unlike previous underwriting cycle studies, this study uses rates-on-line and capacity devoted to satellite insurance as well as loss ratios to determine the applicability of cycles. The sample period encompasses virtually the entire history of the satellite insurance industry, 1968-2010. The results indicate that cycles are present in the minimum and average rates-on-line and in capacity, but not the loss ratio. Regression analysis is carried out on the rate-on-line and capacity variables, and the regression results support the rational expectations/institutional intervention hypothesis and the capacity constraint (capital shock) hypothesis.

The Geneva Risk and Insurance Review (2013) 38, 148-182. doi:10.1057/grir.2013.2

Keywords: satellite insurance; underwriting cycle; rational expectations/institutional intervention hypothesis; capacity constraint (capital shock) hypothesis

Article submitted 22 December 2012; accepted 31 May 2013; published online 17 September 2013

\section{Introduction}

Underwriting cycles in property-liability insurance have been extensively documented over the past half-century in many countries and many lines of insurance. ${ }^{1}$ The underwriting cycle is defined as alternating periods of hard markets in which insurance prices and insurer profitability are high and soft markets with low insurance prices and low insurer profitability. Most of the research documenting the existence of cycles relies on the time series behaviour of published underwriting information on loss ratios and underwriting profits. Theories have arisen to explain

\footnotetext{
${ }^{1}$ For examples, see Smith and Gahin (1983); Venezian (1985); Cummins and Outreville (1987); Doherty and Kang (1988); Grace and Hotchkiss (1995); Lamm-Tennant and Weiss (1997); Chen et al. (1999); Harrington et al. (2008) and Berry-Stolzle and Born (2012).
} 
the existence of underwriting cycles, and these frequently rely on how the insurance product is priced. Some theories emphasize the institutional, accounting and regulatory impact on loss ratios and underwriting profits, while others focus on shocks such as loss, interes, and/or demand and supply shocks. ${ }^{2}$

But insurance is unlike many other goods in that in some lines there may be no price at which customers can buy all of the quantity (coverage) desired. Instead, the insurance product is a package which is a function of rate per dollar of coverage and quantity (the amount of coverage available). Previous empirical underwriting cycle research has been unable to distinguish between the amount of coverage available and the rate for coverage, largely because data is unavailable. Thus as the market hardens, for example, researchers do not know whether increases in the price of insurance are caused by an increase in the price per exposure, a reduction of coverage availability, or both.

The purpose of this research is to investigate the cyclic behaviour of price per dollar of coverage vis-à-vis amount of coverage available in a relatively new, volatile, international and important insurance line: satellite insurance. More specifically, the time series behaviour of rates-on-line and annual industry-wide coverage availability (or capacity) per new satellite launch are analysed to determine whether one or both of these premium components are cyclic. In particular, two prominent underwriting cycle theories, the rational expectations/institutional intervention hypothesis ${ }^{3}$ and the capacity constraint theory ${ }^{4}$, are tested with satellite insurance industry data. ${ }^{5}$ Our analysis provides for a much richer understanding of the performance of this line of insurance over time and the applicability of certain underwriting cycle theories than is possible in previously published underwriting cycle studies.

The satellite insurance industry is a good candidate for an underwriting cycle study. Volatility and cyclicality of results are emphasised in the satellite insurance literature. ${ }^{6}$ Hard and soft markets occur in this industry as well. In the early 1980s a specialist satellite underwriting market emerged, and it became very competitive. Rates were driven down to about 7-8 per cent of the sum insured, and capacity exceeded \$200 million. Unfortunately, in the mid-1980s, the satellite insurance market experienced a crisis due to a series of losses (e.g., Intelsat IV, Palapa B2, Westar VI and the Space Shuttle Challenger) ${ }^{7}$. Rates increased to about 20-30 per cent of the sum insured and capacity shrank below $\$ 100$ million. Coverage was difficult to find for the most valuable satellites.

\footnotetext{
2 E.g., Cummins and Outreville (1987); Browne and Hoyt (1992); Winter (1994); Cummins and Danzon (1997); and Lai et al. (2000), among others.

${ }^{3}$ Cummins and Outreville (1987).

${ }^{4}$ Winter (1994).

${ }^{5}$ Besides capital shocks, interest rate shocks are allowed in the model by including interest rates as an explanatory variable in the regression models used in the study.

${ }^{6}$ E.g., Quarterly Launch Report (2002); Kunstadter (2005, 2007, 2009, 2011).

${ }^{7}$ Doherty (1989).
} 
150

In contrast, in the mid-1990s, the market was soft with low rates and capacity in excess of $\$ 1$ billion. New insurers entered the market at this time. But by the end of the 1990s, the market began to harden after suffering several losses. Some insurers withdrew from the market, including one of the market leaders, the Italian insurer Generali. Capacity decreased, and rates rose rapidly. ${ }^{8}$

The last hard market lasted from 2000 to 2004 but it softened again between 2005 and 2007. Losses in 2007 put the market in a negative position for the year, thereby prompting insurers to increase rates at the beginning of 2008. By the middle of 2008, launch rates stabilised with rates starting to trend downwards until the present. ${ }^{9}$ Thus the satellite insurance market appears to go through repeating sequences of "hard" and "soft" markets, suggesting a cycle.

The data set used in this study consists of time series data from 1968 to 2010, and these data comprise virtually the entire history of the satellite insurance industry. Annual data for rates-on-line and market-wide coverage capacity (availability) for a new satellite launch (i.e., for launch insurance) in addition to underwriting results (i.e., the loss ratio) is used in the analysis. Both rates-on-line and industry-wide coverage availability for launch insurance are analysed to determine whether cycles exist in these variables. Then regression analysis is conducted to determine the primary factors associated with these components of the premium. More specifically, regression equations for rate-on-line and for satellite insurance coverage availability (capacity) are formulated. The regression variables include specific variables for testing the capacity constraint and rational expectations/ institutional intervention hypothesis. To allow for rates-on-line and capacity to be jointly determined, the two equations are estimated using simultaneous equations techniques (i.e., three-stageleast-squares (3SLS)).

This research is important for several reasons. Underwriting cycles are found in rates-on-line and satellite insurance industry coverage availability for a new launch, but not the satellite insurance industry loss ratio. This result is important because it may indicate that previous studies in which cycles were not found in sample countries or lines may in fact be cyclical, if the rate per exposure unit and the coverage per exposure could be controlled for. The results also provide support for the rational expectations/institutional intervention hypothesis for determination of rates-on-line, but not for industry coverage availability. The capacity constraint hypothesis is supported as well. The latter is important because the capacity constraint hypothesis has not been supported by several prominent empirical studies, at least for some lines of insurance. ${ }^{10}$

\footnotetext{
${ }^{8}$ Manikowski (2005a).

9 Space Insurance Market Report (2010).

${ }^{10}$ E.g., Winter (1994); Gron (1994); and Cummins and Danzon (1997), among others.
} 
This research is important, also, because of the importance of the satellite industry. Satellites fulfill a variety of functions ranging from voice/data/video communications globally (e.g., news gathering/distribution, video and data to handhelds), meteorological analysis (e.g., weather forecasting and storm tracking), GPS (e.g., position location, mapping, emergency services), and military and scientific needs. In 2010, worldwide satellite industry revenues were approximately $\$ 168.1$ billion, ${ }^{11}$ doubling since 2004 ( $\$ 82.7$ billion). ${ }^{12,13}$ Without satellite insurance, it would be difficult to obtain financing for purchases and launches of satellites. Further, satellites are purchased and manufactured well in advance of their launch, and volatility in satellite insurance pricing could result in a satellite ready to be launched when satellite insurance rates are very high or capacity scarce. ${ }^{14}$ Thus a well-functioning satellite insurance market is critical to the world.

The remainder of this paper is organized as follows. In the next section a brief overview of the development of the satellite insurance industry and performance statistics are provided. The results from this section form the basis for the Hypotheses section which follows. The Data and the Methodology are discussed in the next two sections, respectively. Results are discussed in the following section. The last section concludes.

\section{The satellite insurance market}

In this section, the development of the satellite insurance market is reviewed from its inception in the 1960s to the present. The performance of this market is reviewed also to provide some preliminary evidence about its susceptibility to underwriting cycles.

\section{Satellite insurance development}

Until the mid-1960s most satellites that were launched were related to the military aims of the United States and Soviet Union. Projects were uninsurable because launch vehicles were unreliable and most payloads were experimental. ${ }^{15}$ Therefore, the risk was retained by governments and the space agencies that financed the flights.

${ }^{11}$ The total amount can be broken down as follows: Satellite Services (60 per cent), Satellite Ground Equipment (31 per cent), Satellite Manufacturing (6 per cent) and Satellite Launch Industry (3 per cent).

12 State of the Satellite Industry Report (2006 and 2011).

13 The National Security Telecommunications Advisory Committee (NSTAC) Satellite Task Force Report to the President stated, "The commercial satellite industry is critical to our national, economic, and homeland security" (NSTAC, 2004).

${ }^{14}$ A futures market for satellite insurance does not exist at this time.

15 Manikowski (2005b). 
The American Communication Satellite Corporation (ACSC), founded in 1962, was the first company devoted to using new satellite technology for commercial purposes and was interested in obtaining satellite insurance. On 6 April 1965, ACSC obtained the first space insurance policy to protect the first commercial geostationary communication satellite, Early Bird (an Intelsat I-F1 satellite). ${ }^{16}$

At the beginning, satellite risk was mainly placed in the international aviation market, simply because this market was more familiar with the problems of space flight than other insurance markets. Over time, the complex and technical features of this line of insurance in combination with the possibility of large losses has resulted in a limited number of insurers offering this coverage. ${ }^{17,18}$ At present, satellite insurers comprise a relatively small but international community within the insurance industry, with satellite insurance centres in Europe (London, Paris and Munich) and in the United States (New York and Washington, DC).

Since a limited number of insurers provide this insurance and losses are large when they occur, some believe that a loss in one area of the satellite insurance industry directly influences the ability of insurers to cover other satellite-related risks. ${ }^{19}$ That is, the same players underwrite launch and in-orbit insurance so that losses, when they occur, all come from the same basic pool. A summary of the different types of satellite insurance policies appears in Appendix A.

\section{Satellite insurance market performance}

The basic participants in the satellite insurance market include: ${ }^{20}$

16 The policy covered only material damages to the satellite prior to lift-off (pre-launch insurance for \$3.5 million) and third-party liability during launch for \$5 million (Zocher, 1988a; Margo, 2000).

${ }^{17}$ Bannister (1992).

${ }^{18}$ Some of the features of satellite insurance that make it so difficult to insure include: potential large losses for each launch event; most losses are total; difficulties in solving problems with satellites that occur in outer space; difficulty in determining the causes of accidents; the small number of insured objects; lack of risk homogeneity; the possibility of large loss accumulation; the covered object may be in a hostile space environment; and losses can occur not only from outside forces but from a breakdown in the satellite or rocket itself.

${ }^{19}$ Unlike many other areas of insurance, the satellite insurance industry does not benefit from a large homogeneous exposure pool to which the law of large numbers can be applied. Some insurers have concluded that the satellite insurance industry requires a much higher number of launches (possibly 600 launches with a variety of launch vehicles) to accurately measure risk from homogeneous exposures in this industry (Hollings, 1988). In contrast, in the period 1968-2010, there have been a total of 643 insured launches, with satellite technology changing dramatically over this period. According to Hollings (1988), there are too few statistical events to estimate failures with reliability in this industry. Of course, risks do not have to be homogeneous to be diversifiable (and hence insurable), as evidenced by the types of risk insured by Lloyds of London. However, in general, it can be difficult to find insurance for large, unique risks.

${ }^{20}$ Lys (1999); Manikowski (2004). 
- insurers and reinsurers: ACE, AXA, Elseco, Global Aerospace, Lloyd's of London (different syndicates), Munich Re, SCOR, Spaceco, Swiss Re, XL, etc; ${ }^{21}$

- brokers: Aon-International Space Brokers, Marsh Space Projects, Willis Inspace, etc.;

- manufacturers: Astrium, Boeing, Lockheed Martin, Space Systems Loral, Orbital, TAS, etc.;

- launching agencies: Arianespace, China Great Wall Corporation, International Launch Services, Sea Launch, United Launch Alliance, etc.;

- operators: Arabsat, Eutelsat, Globalstar, Inmarsat, Intelsat, JSAT, SES, Telesat Canada, etc.; and

- users: TV stations, telecoms, banks, car manufacturers, etc.

Moreover, government agencies from such countries as the United States, Russia, Japan, China, India and from Europe-represented by the European Space Agency or by individual national agencies within Europe-may also participate in different roles.

Satellite operators, as owners, are usually the most interested parties for buying insurance. Currently 50 operators have 306 satellites in orbit and only 176 of these are insured. $^{22}$ This is because usually only commercial satellites are insured (launch and in-orbit insurance), as they generate revenues. By contrast, most scientific and military satellites have no direct revenues associated with them, and they are not insured. However other parties may seek insurance: launch agencies sometimes need insurance policies for the launch; manufacturers as a rule use pre-launch insurance. Government agencies usually insure their commercial missions (especially during launch), although NASA self-insures ${ }^{23}$ what it launches. ${ }^{24}$ Similarly, the Russian Federal Space Agency also does not usually use insurance; however, they purchased third-party liability insurance in case failure of the MIR Station would cause it to fall into the Pacific ocean (23 March 2001). They paid about U.S.\$1 million premium for a U.S.\$200 million limit of responsibility. ${ }^{15}$

To gauge the size of the satellite insurance market and its risk characteristics, Figure 1 depicts the orbital launch attempts since 1957. The largest number of annual launch attempts occurred during the period 1966-1990. Launch numbers have been

${ }^{21}$ Market concentration is not high-the Herfindahl Index is low (0.0486 for year 2010). Detailed market share information appears in Appendix C. In the satellite insurance market, market share is measured by capacity not by premium, as is commonly done in other insurance markets. Data about written premium by each underwriter is not available-it is treated as sensitive and is not published. However, market shares in capacity and premiums are usually quite similar.

${ }^{22}$ Kunstadter (2012).

${ }^{23}$ After the tragedy of the Columbia space shuttle, NASA received a total of 66 claims for property damage and loss of cattle due to the debris of the orbiter that fell on a sparsely populated area near the Texas/Arizona border. Claims totalled U.S. $\$ 500,000$ which NASA had to pay itself.

${ }^{24}$ Stahler (2003). 
declining since the demise of the Soviet Union and the ensuing loss of "Cold Warinduced" military launches. While there was a recovery in launch numbers at the end of the 1990s due to the introduction of mobile satellite constellations in Low Earth Orbit (LEO), this recovery now appears to be over.

Figure 1 also indicates the failure rate. The failure rates during the early years of this industry were much higher than they have been in recent years. A significant decrease in the number of failed launches occurred beginning in 1972. The failure rate in recent years has been very low - in the last decade (2001-2010) there has been only 3-4 launch failures annually. In 2010 there were four launch vehicle failures out of 74 attempts for a 5.4 per cent failure rate, compared with failure rates exceeding 10 per cent in some years in the 1990s.

The total number of launches in Figure 1 includes different kinds of space missions, such as commercial, military and scientific projects. ${ }^{25}$ Figure 2 indicates the number of total launches compared with the number of insured launches from 1968 to 2010. Figure 2 indicates that most launches are not insured, although the number of launches that are insured has grown significantly since the inception of the satellite industry. In the 1970s and 1980s, the proportion of launches insured was relatively small but growing. In 2010, 30 satellites in 19 insured launches were insured, ${ }^{26}$ and this is far less than at the end of the 1990s when whole constellations of satellites were insured. From an insurance perspective, the most important launches are commercial flights to Geostationary Earth Orbit (GEO). ${ }^{27}$ GEO satellites have accounted for about 20 per cent of total launches in each year. ${ }^{28}$

The satellite insurance industry is shaped by a number of forces: limited number of new insurance contracts annually (usually no more than 30 ), ${ }^{29}$ large potential losses (e.g., in excess of $\$ 250$ million), participation of several insurers for one launch due to the large loss potential and a limited number of underwriters (i.e., 30-40). All this has led to overall volatility in the industry. Volatility in premiums and claims is

${ }^{25}$ For example, in 2010 there were a total of 74 launches (delivering 110 payloads into orbit), 23 of which were commercial (33 payloads) and 51 non-commercial (77 payloads, including 31 for civil government purposes and 29 for military use) (Federal Aviation Administration (FAA) 2010).

26 Two or more payloads (satellites) may be included in one launch (i.e., so-called dual or multiple launches). The satellites and launch may both be insured or just the launch may be insured. Thus there is a difference between the number of insured launches and insured satellites.

27 A GEO is a circular orbit $35,786 \mathrm{~km}$ (22,237 miles) above the Earth's surface, in the same plane as the Earth's equator. A satellite in this orbit has an orbital period equal to the Earth's sidereal period of rotation $(23 \mathrm{~h} 56 \mathrm{~min} 4 \mathrm{~s})$. The satellite therefore appears stationary with respect to the Earth-hence the name "geostationary". This also means that the satellite can be given an orbital position related to the line of longitude it is stationed above (Williamson, 1990a).

${ }^{28}$ Todd (2006); Federal Aviation Administration (FAA) (2010).

29 There are about 30 new insurance contracts yearly connected with launches of new satellites (launch insurance); and these represent about 75 per cent of the total world satellite insurance premium. There are about $130-150$ policy renewals (in-orbit insurance). 


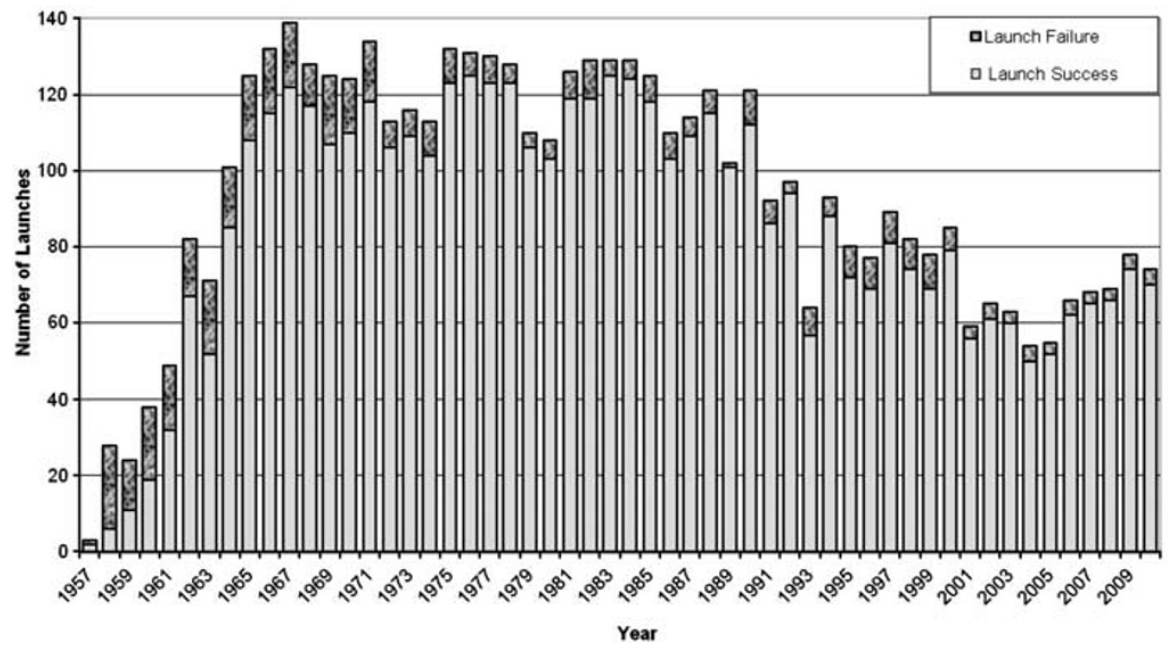

Figure 1. Orbital launch attempts: 1957-2010.

Source: Todd (2006) and Federal Aviation Administration (FAA) (2010).

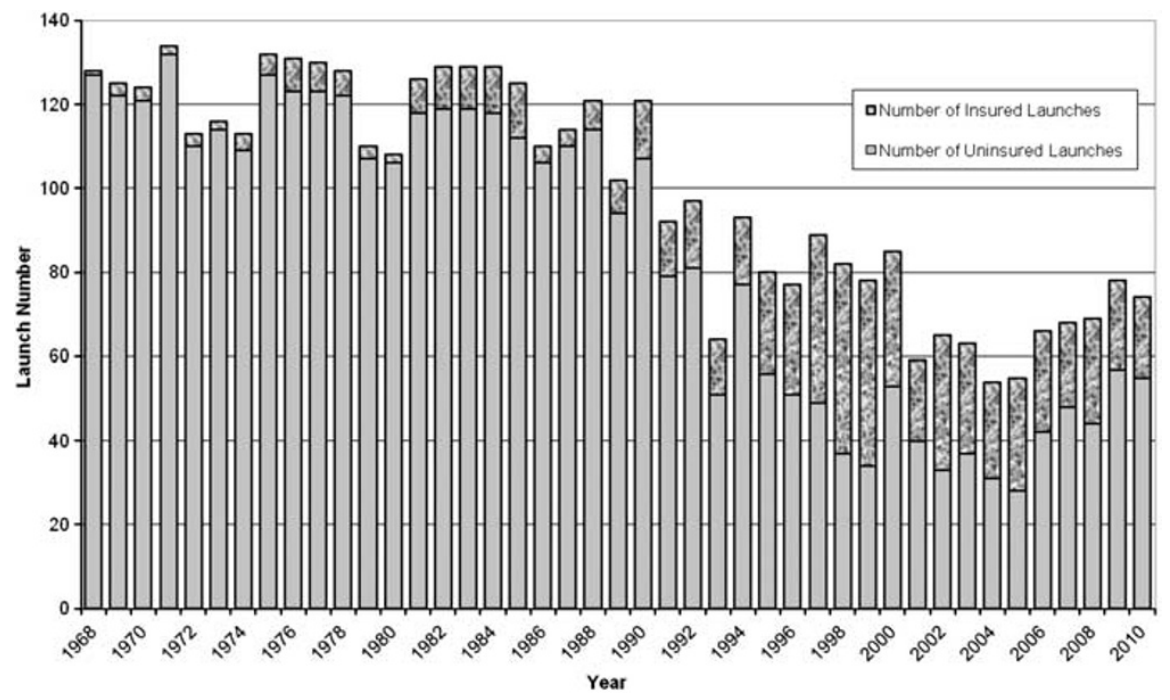

Figure 2. Insured and uninsured launches: 1968-2010.

Source: Todd (2006) and Space Insurance Market Report (2010). 
depicted in Figure 3. This figure contains premiums and claims in this industry from 1968 to 2010.

Figure 3 indicates that a period of premium growth occurred beginning with the 1980s through the first half of the 1990s, and in 1997 premiums exceeded \$1 billion. But a series of losses in 1998 and 1999 dampened the market. ${ }^{30}$ Claims have outstripped premiums in several years, especially in 1998 and 2000. One can observe the same phenomenon in a slightly different way by looking at loss ratios over time in Figure 4. The loss ratio reached a minimum of about 7 per cent (not including years free of any loss) in 1989, and a maximum of 570 per cent was reached in 1979.

Premiums for satellite insurance are affected by the coverage limits available for this coverage and by the rate-on-line. Both of these factors have demonstrated volatility over time as well. Figure 5 contains the minimum rate-on-line, the average rate-on-line and capacity for launch insurance. With respect to capacity, each company has a maximum dollar amount of insurance (i.e. capacity) it can offer for an individual satellite or launch risk. Most insurers report a maximum theoretical capacity they can provide for an individual risk. However, many insurers only allocate part of their theoretical capacity to any specific launch or in-orbit risk and may not use their full theoretical capacity. ${ }^{31}$ Figure 5 indicates that capacity grew steadily in the industry initially. However capacity declined in the mid-1980s due to a series of losses, including the loss of the Space Shuttle Challenger in $1986 .{ }^{32}$ But capacity began to grow again a few years later and reached its peak in 1999 at $\$ 1.3$ billion. ${ }^{33}$ From that peak, capacity steadily shrunk to the end of $2004 .{ }^{34}$ However, since 2005 it has been growing again.

Not only does Figure 5 indicate wide variation in rates-on-line and capacity, but these factors also appear to be cyclical. Further, it does not appear that capacity and rates vary directly together. For example, capacity appears to be at an all-time high in 1999 when the average rate is relatively low. An inverse relationship appears to exist between capacity and rates in other years as well. This is confirmed by the correlation coefficient between capacity and the average rate, which is -0.66 for the period 1968-2010.

${ }^{30}$ From its inception in 1965 until 1977, the satellite insurance industry remained free of claims. But this was not because there were no losses. Rather it was customary to insure several satellite launches under one policy and to consider one launch failure as the policy deductible. Because of this, premium rates were so low that the first claim insurers were responsible for (the loss of an OTS-1 satellite in 1977) consumed all premiums collected by the industry until that time.

${ }^{31}$ Typically there is more capacity available for launch risks than in-orbit risks due to the fact that some insurers find launch risks more attractive than in-orbit risks (Space Insurance Market Report, 2010).

32 Gobbo (1991).

33 Fabre (2002).

${ }^{34}$ Wade and Gubby (2004). 


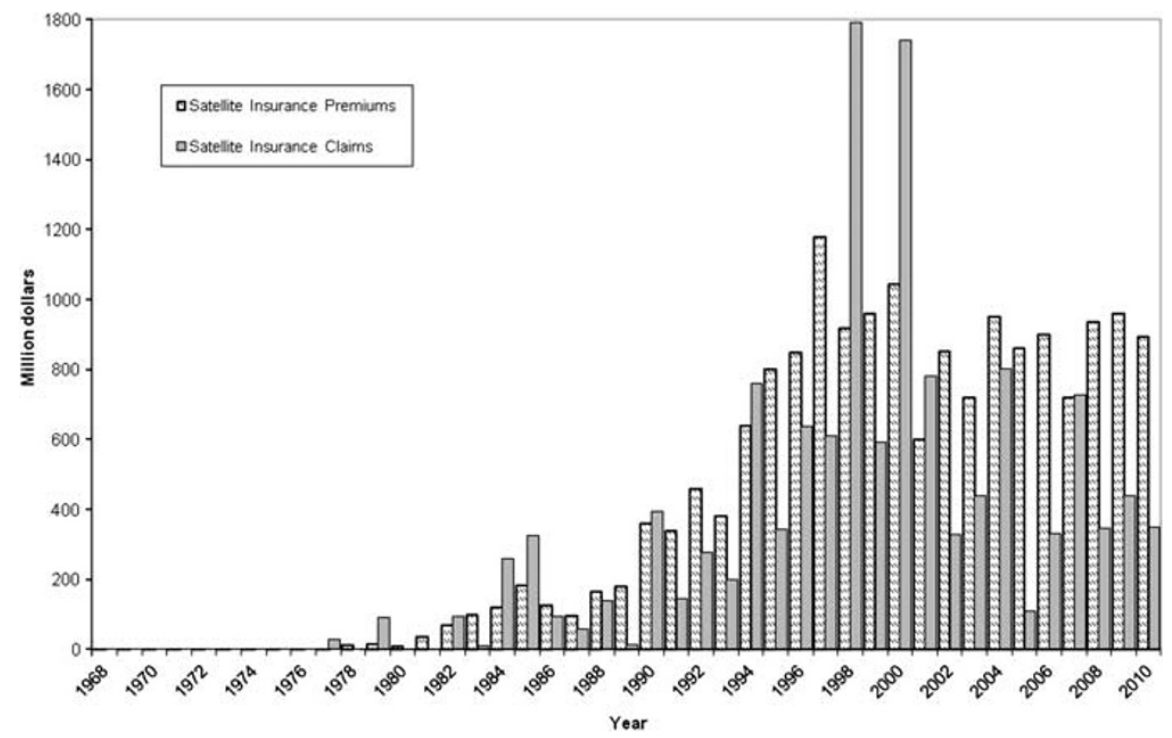

Figure 3. Satellite insurance premiums and claims: 1968-2010.

Source: Kunstadter (2011) and Space Insurance Market Report (2010).

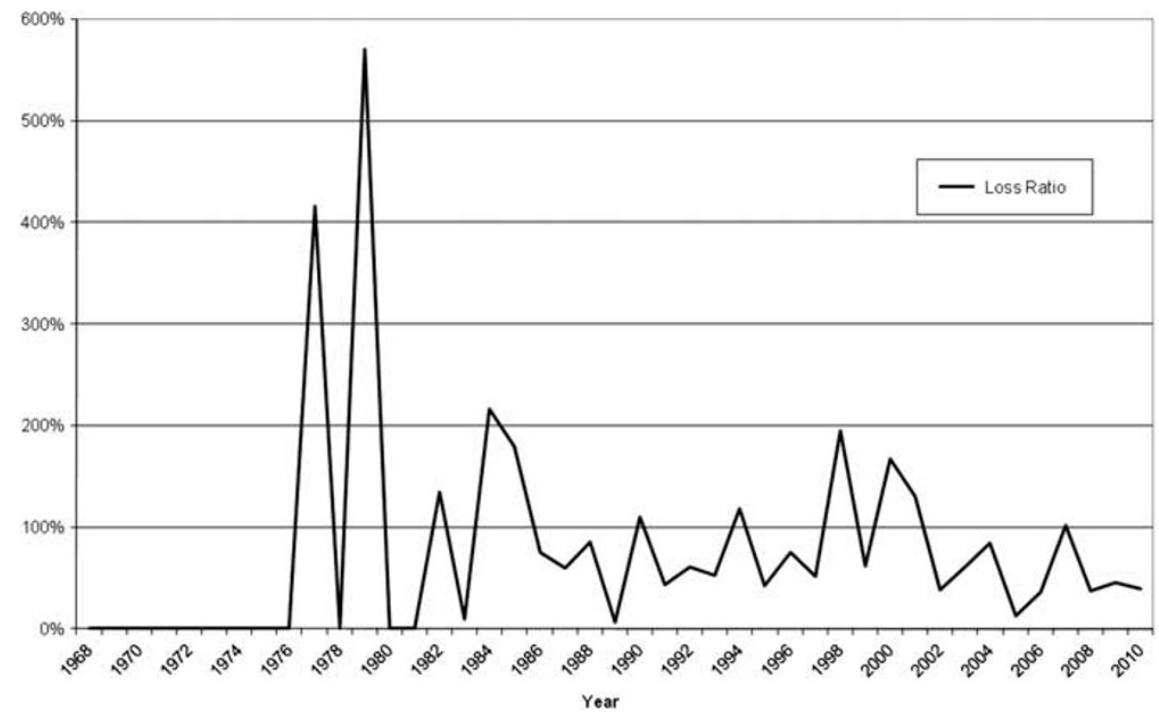

Figure 4. Satellite insurance loss ratio: 1968-2010.

Source: Calculated on the basis of Figure 3. 


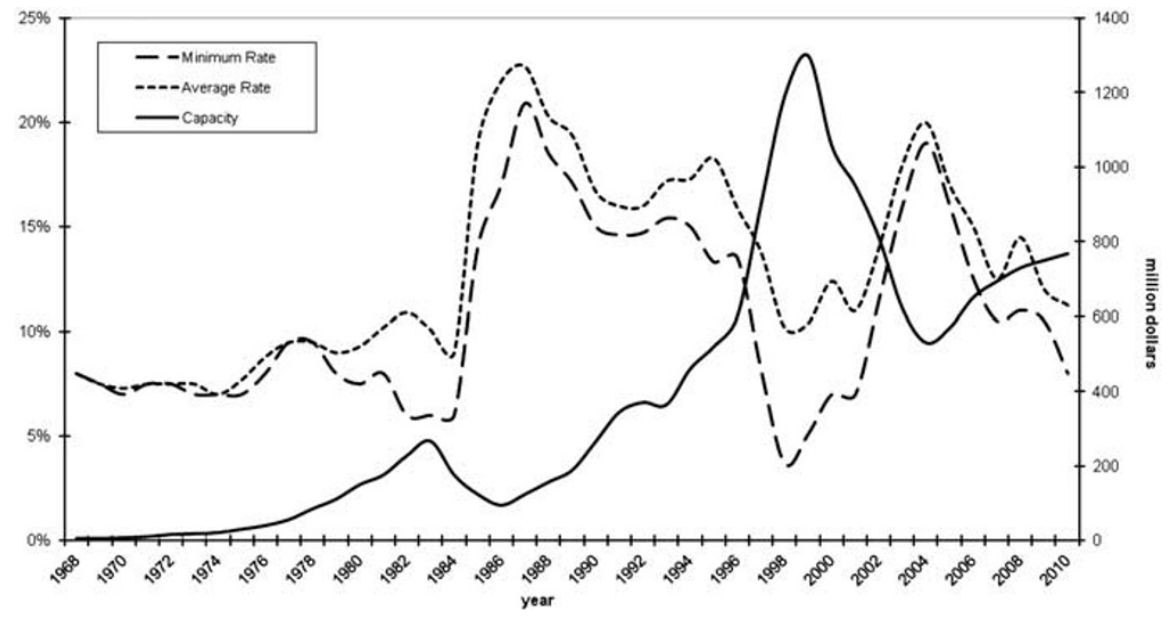

Figure 5. Capacity vs. rate-on-line: 1968-2010.

Source: Space Insurance Market Report (2010).

Historically, rates were set too low in the early years of satellite insurance, which meant that total premium income was eroded by a few claims. Traditionally, rates have been set in reaction to claims experience (recent market experience) ${ }^{35}$ rather than by statistical analysis of the launch and in-orbit record. ${ }^{36}$ The evidence for this can be found in Figure 6. From this figure it appears that increases in rates occur after claims increase.

It is interesting to consider how capacity in the satellite insurance industry varies with respect to capacity in the worldwide insurance industry. Unfortunately, capacity data is not available for the worldwide insurance industry over the period 1968-2010. However, some approximate indications of industry capitalisation might be gleaned from trends in the data on the top 100 reinsurers reported by Standard \& Poor's and from U.S. professional reinsurers, which are portrayed in Figure 7. In interpreting this figure, it is important to keep in mind that satellite insurance capacity is defined in terms of the limits on policies available in the market, while the data for reinsurers

${ }^{35}$ However other factors also affect rates. The main factors include: (1) Technology Aspects (e.g., the heritage of the: launch vehicle, satellite platform and satellite payload); (2) Scope of Insurance Contract (e.g., requirements, loss definitions, salvage proposals, period of coverage); (3) Market Capacity (i.e., Overcapacity leads to too many insurers endeavoring to underwrite the same risks; this has a downward effect on rates. In an oversubscribed market, premium rates charged may be below the "technical rate" associated with the risk), as well as (4) Recent performance (e.g., rates tend to increase if satellites and launch vehicles of similar design to those chosen by the insured suffer failures. In general, rates for proven technologies are much cheaper than an untried design.)

36 Space Insurance Briefing (2001). 


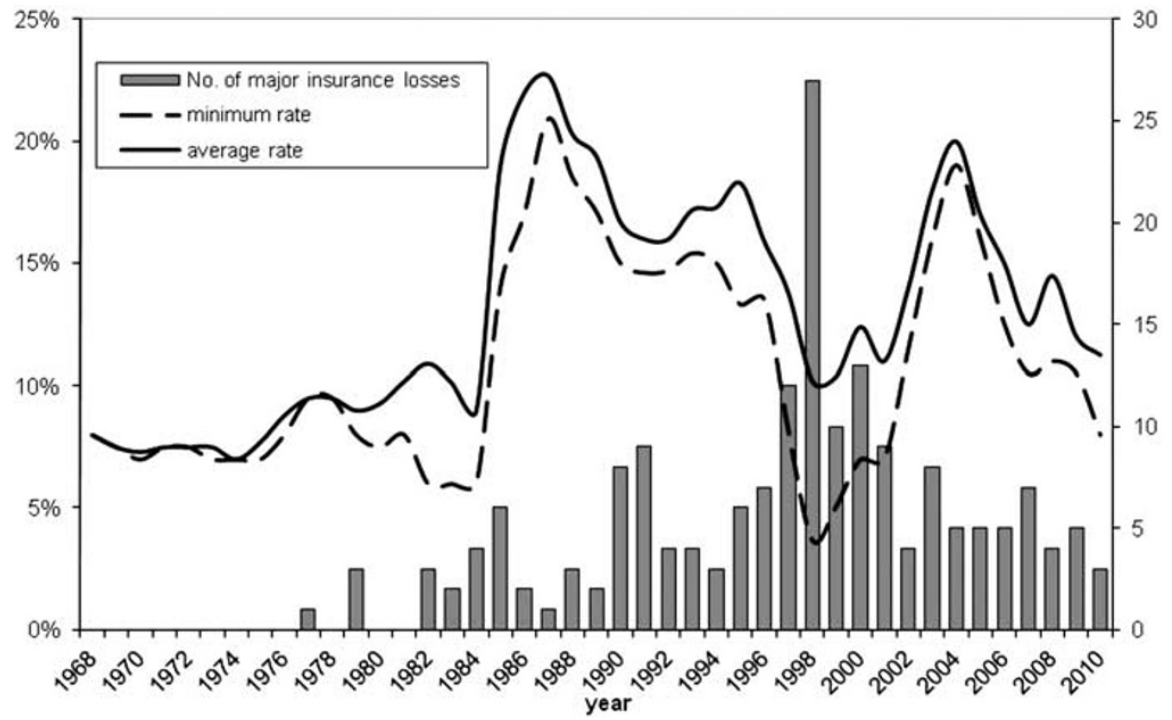

Figure 6. Number of losses vs. rate-on-line: 1968-2010.

Source: Space Insurance Market Report (2010).

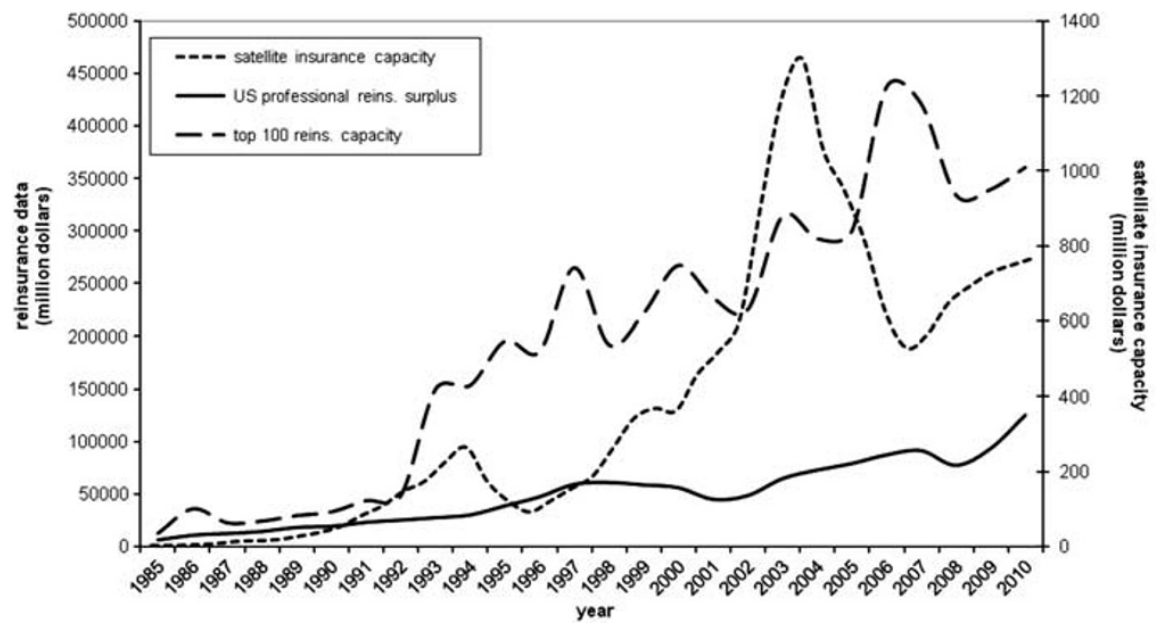

Figure 7. Satellite insurance capacity vs. reinsurance capacity and surplus: 1985-2010.

Source: Space Insurance Market Report (2010), Best's Aggregates \& Averages (various years) and Reactions (various years). 
160

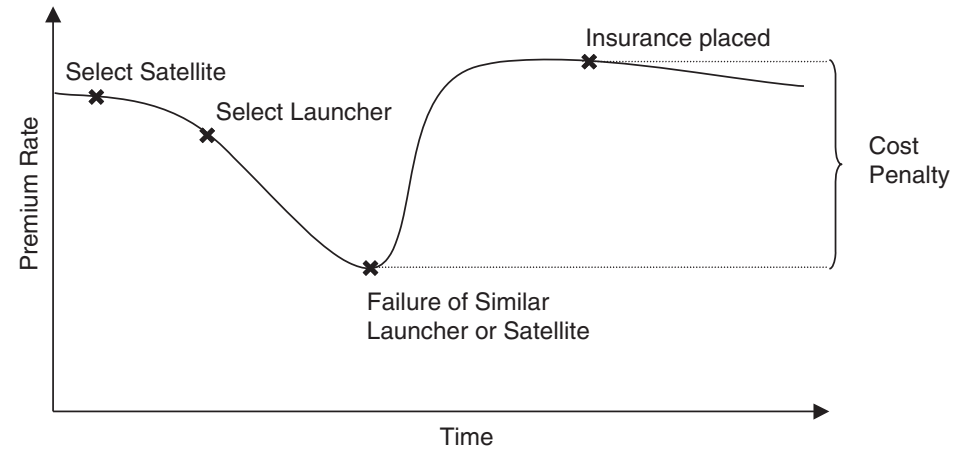

Figure 8. Impact of failures on premium rate.

Source: Space Insurance Briefing (2001).

is based on their capital or surplus. This figure suggests that there is an approximate connection in trends between worldwide capitalisation (as proxied by the data in Figure 7), and satellite insurance industry capacity. Hence the condition of the overall insurance industry may be important when analysing the satellite insurance industry.

Finally, the performance of the satellite insurance industry may have important repercussions on the launching of satellites and their timing. The satellite insurance market appears to many to be an unpredictable, cyclic market. Thus a purchaser of satellite insurance should monitor developments in the satellite insurance market to assess the best time for placing their risk in the market. Of course, there is always the possibility that an insured might be forced for a variety of reasons to purchase insurance when the market is at its peak. Figure 8 illustrates how this may occur.

Thus developments in the satellite insurance market can have an important impact on costs (prices) associated with the services that satellites provide to buyers (consumers).

\section{Hypotheses specification}

The preceding section has demonstrated graphically that there is a connection between satellite insurance rates-on-line and past losses. The rational expectations/ institutional intervention hypothesis associates insurance prices with past losses. ${ }^{37}$ In addition, there also appears to be a connection between rates-on-line and capacity (coverage availability). Several strains of the underwriting cycle literature associate insurance prices with capacity. ${ }^{38}$ Formal hypotheses concerning these factors and the satellite insurance industry are developed in this section.

\footnotetext{
${ }^{37}$ Cummins and Outreville (1987); Lamm-Tennant and Weiss (1997).

${ }^{38}$ E.g., Harrington and Niehaus (2000).
} 


\section{Rational expectations/institutional intervention hypothesis}

Cummins and Outreville ${ }^{3}$ develop a model in the context of rational expectations in which external factors can produce second-order autocorrelation among underwriting profits. One such external influence is institutional lags attributed to data collection, regulation and policy renewal periods. Accounting reporting conventions also contribute to the autocorrelation. Hence, according to their research, current prices would be expected to be related to accounting losses in the prior two years. Lamm-Tennant and Weiss, ${ }^{39}$ among others, test this theory using a time series of underwriting results for a number of different countries.

But insurance prices are found by multiplying its two components together, the rate-on-line and the amount of coverage provided. ${ }^{40}$ The rational expectations/ institutional intervention hypothesis does not distinguish between these two components. ${ }^{41}$ Hence in this research the relationship between both of these components of price and past loss experience are investigated:

Hypothesis la Rate-on-line is positively associated with past losses.

A corollary hypothesis can be formulated about the relationship between the quantity of coverage available for new launches and past losses. That is, increasing the rate-on-line is one way in which prices can be increased when unfavourable past loss experience develops. Prices can also be effectively increased if the quantity of coverage available is reduced when unfavourable past loss experience develops, even if the rate-on-line remains the same. This leads to Hypothesis $1 \mathrm{~b}$ :

Hypothesis $1 b$ The maximum amount of coverage available for a new satellite launch is negatively related to past losses.

Note that an increase in the rate-on-line or a decrease in amount of coverage availability for a new satellite launch would provide evidence in favour of the rational expectations/institutional intervention hypothesis. In fact news stories are replete with examples of premiums increasing at the same time that coverage is reduced during hard markets and insurance crises. ${ }^{42}$ Thus it is worthwhile to confirm whether both rate-on-line and coverage availability are responsive to past losses.

${ }^{39}$ Lamm-Tennant and Weiss (1997).

${ }^{40}$ Rate-on-line is defined as the amount charged per $\$ 1000$ of coverage.

${ }^{41}$ Although rates-on-line and capacity are not accounting numbers, past loss history may still have an impact on capacity and rates-on-line due, for example, to such factors as institutional data collection lags.

${ }^{42}$ E.g., Harrington and Danzon (2000); Harrington and Niehaus (2000). 


\section{Capacity constraint hypothesis}

The rational expectations/institutional intervention hypothesis helps to explain the appearance of cycles. But real crises associated with factors such as capital shocks also occur. Winter ${ }^{4}$ and Gron $^{43}$ develop a capital shock model of insurance prices in which price is inversely related to capacity (capacity constraint hypothesis). Thus if the capacity constraint hypothesis is valid, we should find that as the amount of coverage available for writing a new satellite launch increases (i.e., capacity increases) then the rate-on-line decreases. This leads to Hypothesis 2:

Hypothesis 2 Satellite insurance rates are inversely related to the amount of satellite insurance coverage available for a new satellite launch.

But this gives rise to the question of how capacity for satellite insurance is decided by insurers. According to Hypothesis $1 \mathrm{~b}$ above, past losses would play a role in capacity determination. But it is also possible that the amount of industry coverage available for a satellite launch is related to how much the market is willing to pay for coverage (i.e., the rate-on-line). That is, maximum coverage amounts for the satellite insurance industry and the rate-on-line may be determined simultaneously. The latter is a testable hypothesis:

Hypothesis 3 Satellite insurance rates and maximum available coverage are determined simultaneously.

A potentially viable alternative hypothesis might be that market forces determine the rate-on-line for satellite insurance, and that satellite insurance underwriters base the maximum amount of coverage they are willing to provide on this market rate. Prior underwriting studies have not investigated this issue at any length, mainly because the necessary data was unavailable.

\section{Data}

The data for the satellite insurance analysis covers the period 1968-2010, and this period includes almost the entire history of satellite insurance. This data is obtained directly from market participants: insurance brokers, ${ }^{44}$ underwriters ${ }^{45}$ and additional

\footnotetext{
43 Gron (1994).

${ }^{44}$ These include, AON-International Space Brokers, Marsh Space Projects, and Willis Inspace.

45 Among others, AXA Space, La Reunion Spatiale, Munich Re, SCOR, Atrium Space Insurance Consortium and USAIG provided information.
} 
companies (e.g., Ascend ${ }^{46}$ and Sciemus ${ }^{47}$ ); thus it is full and representative. ${ }^{48}$ Underwriting information for claims, premiums, loss ratios, rates-on-line and capacity are used in the analysis. Claims are defined as claims paid from launch insurance and satellites-in-orbit insurance. Premiums are written premiums from launch insurance and satellites-in-orbit insurance. The loss ratio is defined in this study as the ratio of claims to premiums, as data for losses incurred is unavailable. Rates-on-line pertain to launch plus one year of in-orbit operations. The minimum rate is the rate for the best (i.e., most reliable) risk or technology. The average rate is the arithmetic mean of all individual rates. ${ }^{49}$ Capacity is the sum of the maximum amount that each underwriter is willing to provide on one satellite for launch insurance. $^{50}$

Supplemental data such as macroeconomic variables were obtained from the U.S. Department of Commerce, Statistical Abstract of the U.S., various years. Insurance industry variables were obtained from A. M. Best Company, Best's Aggregates \& Averages, various years and Standard \& Poor's, Reactions, various years. All other remaining satellite insurance data was obtained from press stories or reports ${ }^{51}$ about the satellite insurance industry (e.g., total number of launches).

\section{Methodology}

The analysis of underwriting cycles in the satellite insurance industry is undertaken in two stages. First, tests are performed to determine whether underwriting cycles exist in this line, and the length of the cycle if relevant. Next, the methodology for

${ }^{46}$ For over 25 years, Ascend (previously Airclaims) has provided independent, accurate information and analysis to the world's major space programmes and finance and insurance markets.

${ }^{47}$ Sciemus (in cooperation with QinetiQ) created SpaceRAT (Risk Assessment Tool) —a system to quantify risks associated with geostationary communications satellites. The system uses an extensive database of satellites to produce a risk profile for each satellite's critical component. This forms the basis of the risk profile of the spacecraft itself. The SpaceRAT database is currently the most comprehensive database of satellite performance available anywhere in the world. It includes all satellites insured over the last 40 years.

${ }^{48}$ For example, the main satellite insurance brokers-AON-International Space Brokers, Marsh Space Projects and Willis Inspace-publish regular reports that include data on premiums, claims, rates and capacity starting from the early 1980s. Similar statistics are delivered at speeches at the biannual International Space Conferences (e.g., Kunstadter, 2005, 2007, 2009, 2011). Earlier data was taken from other available publications (Hughes, 1984; Zocher, 1988a, b).

49 Data is not available to compute a weighted average rate, where the weight is defined as the sum of the premiums of company $i$ multiplied by the proportion of total satellite premiums written by company $i$.

${ }^{50}$ Recall that this capacity is theoretical capacity, since the underwriter may not actually apply the maximum amount when underwriting a risk. About this and other meanings of capacity see: Manikowski (2013).

${ }^{51}$ Federal Aviation Administration (FAA) (2010). 
testing the hypotheses is discussed. This discussion includes a description of the regression models as well as issues associated with using time series data (unit roots, cointegration and autocorrelation).

\section{Underwriting cycle determination}

A second-order autoregressive model proposed by Venezian ${ }^{52}$ is used to obtain the parameters for testing for the existence of the underwriting cycle. More specifically, parameters needed to measure the cycle period are obtained by estimating the following autoregressive model with ordinary least squares:

$$
P_{t}=a_{0}+a_{1} P_{t-1}+a_{2} P_{t-2}+\omega_{t},
$$

where $P_{t}$ is the variable potentially subject to a cycle, $t$ is a time subscript and $\omega_{t}$ is a random error term assumed to be normally distributed with a mean of zero. Several dependent variables are tested: the average satellite insurance rate, the minimum satellite insurance rate, satellite insurance capacity and satellite insurance loss ratios.

A cycle is present if $a_{1}>0, a_{2}<0$ and $\left(a_{1}\right)^{2}+4 a_{2}<0 .{ }^{52}$ The model coefficients can be used to estimate cycle periods for the variables of interest, assuming that the conditions necessary for a cycle exist. The cycle period is expressed as follows:

$$
T=\frac{2 \pi}{\cos ^{-1}\left(\frac{a_{1}}{2 \sqrt{-a_{2}}}\right)} .
$$

\section{Analysis of satellite insurance rates and capacity}

Regression models are used to test Hypotheses 1-3. However, before regression can be conducted, the data must be tested for problems commonly associated with time series data. First, unit root tests are conducted on the regression variables to determine whether the variables are stationary. ${ }^{53}$ Augmented Dickey-Fuller unit root tests indicated that all variables had a unit root using a 5 per cent level of significance for the test. (See Appendix D for these results.) Therefore, cointegration analysis between the dependent variables and the regression variables was conducted to determine whether the regression variables were cointegrated (i.e., I(1)). ${ }^{54}$ Cointegration of rank 1 did not exist among most of the regression variables. ${ }^{55}$

52 Venezian (1985).

${ }^{53}$ Dickey and Fuller (1979).

${ }^{54}$ Pindyck and Rubinfeld (1998).

55 This result is based on a 1 per cent critical value for the test statistic. The exceptions are for the minimum rate and lag 2 of the loss ratio and the minimum rate and lag 3 of the loss ratio. Nevertheless, taking a first difference with variables that are stationary is not necessarily a problem econometrically. 
(See Appendix D for the results of these tests.) ${ }^{56}$ Therefore, transformation of the variables was performed before analysis was conducted.

All variables were transformed by expressing them in first difference form (i.e., $\left.\Delta x_{t}=x_{t}-x_{t-1}\right)$. Augmented Dickey-Fuller unit root tests on the first differenced variables indicated that these variables were stationary, and therefore appropriate to use for regression analysis. ${ }^{57}$ (See Appendix D for the results of these tests.)

Two regression models are formulated to test the hypotheses. In the first regression model, the satellite insurance rate is assumed to be a function of capacity, past losses and control variables consisting of the discount rate, and the demand for satellite insurance. In the second regression model, capacity is assumed to be a function of the satellite insurance rate, past loss ratios and other control variables such as the condition of the overall insurance industry. These models are discussed more fully below.

\section{Satellite insurance rate model}

The satellite insurance rate model is specified as:

$$
\begin{aligned}
\Delta \text { Rate }_{t}= & \alpha+\beta_{1} \Delta \text { Loss ratio }_{t-1}+\beta_{2} \Delta \text { Loss ratio }_{t-2}+\beta_{3} \Delta \text { Loss ratio }_{t-3} \\
& +\beta_{4} \Delta \text { Capacity }_{t}+\beta_{5} \Delta \text { Demand }_{t}+\beta_{6} \Delta \text { Interest rate }_{t}+\beta_{7} \text { Trend }_{+} \varepsilon_{t},
\end{aligned}
$$

where $t$ indicates year and $\varepsilon_{t}$ is assumed to be a normally distributed random error term with a mean of zero. The dependent variable, changes in the real satellite insurance rate or $\Delta$ Rate $_{t}$, is defined as the real rate amount that is multiplied by the coverage amount to determine the premium (i.e., rate-on-linexcoverage amount $=$ premium). Change in the real minimum rate-on-line (i.e., the rate applied for the most reliable risks and technology) is used as the dependent variable.

The rational expectations/institutional intervention hypothesis posits that autocorrelation exists in underwriting prices because they incorporate information about accounting profits for the prior 2 years. ${ }^{3,58}$ If current rates-on-line are formed based at least partly on past underwriting profits, then current rates-on-line might be directly related to loss ratios for the 3 prior years. Therefore, changes in the lagged loss ratios from the 3 prior years are included in the model. ${ }^{39}$ The expected signs for changes in the lagged loss ratio variables are positive.

The real value of the capacity available for a new launch is included to test the capacity constraint (capital shock) hypothesis. Capacity as it is defined here is stated in terms of the real dollar amount of the maximum coverage for launch insurance available in the market for year $t$. The capacity constraint hypothesis posits that a negative relationship exists between price and the availability of coverage that

\footnotetext{
${ }^{56}$ Also, Choi et al. (2002) do not find relative capacity to be cointegrated with underwriting profit.

57 A 5 per cent significance level is used for this analysis.

${ }^{58}$ This is because policies are written throughout the year so that accounting profits in year $t-1$ reflect losses in years $t-1$ and $t-2$, while accounting profits in year $t-2$ reflect losses in years $t-2$ and $t-3$.
} 
166

insurers are capable of providing. ${ }^{59}$ That is, the maximum coverage available for launch insurance should be related to the capability of the satellite insurance industry to write this business, everything else held equal. This capability should be related to the financial resources or capital allocated to this line. Under the capacity constraint theory, the coefficient for this variable should be negative.

The other control variables in this model include demand, interest rates and a trend. Demand for satellite insurance is expected to be related to price, with increases in demand associated with increases in prices. Demand is proxied by the number of total launches in a given year. (Recall that only a fraction of total launches is insured in a given year.) Considerable prior literature has shown that insurance prices are inversely related to discount rates. ${ }^{60}$ Therefore a real mid-term interest rate is included in the model, the U.S. 5-year Treasury bond rate, and the expected sign of this variable is negative. ${ }^{61}$ Finally, a trend variable is included in the model to take account of increasing familiarity with this industry over time; that is, as more information about satellites' performance unfolds over time, insurers might adjust the rates that they charge. The coefficient may be positive or negative for this variable depending upon the experience that has unfolded.

\section{Satellite insurance capacity model}

The satellite insurance capacity regression model is specified as:

$$
\begin{aligned}
\Delta \text { Capacity }_{t}= & \alpha+\delta_{1} \Delta \text { Loss ratio }_{t-1}+\delta_{2} \Delta \text { Loss ratio }_{t-2}+\delta_{3} \Delta \text { Loss ratio }_{t-3}+\delta_{4} \Delta \text { Rate }_{t} \\
& +\delta_{5} \Delta \text { New Satellite Value } \\
+ & +\delta_{6} \Delta \operatorname{Pr}{\text { emiums Written } / \text { Surplus }_{t}} \\
& +\delta_{7} \Delta \text { Total Launch Failed } \%_{t}+\delta_{8} \text { Trend }+\nu_{t},
\end{aligned}
$$

where $v_{t}$ is the error term and the subscript $t$ is defined as before. The dependent variable in this regression was described earlier. The control variables in this model can be categorised in terms of past underwriting experience in this line, the minimum satellite insurance rate-on-line and overall insurance industry conditions. These variables are described below.

59 The capacity constraint theory predicts that price is inversely related to capacity (surplus), while the risky debt hypothesis predicts that price should be directly related to capacity (i.e., financial quality). However, the two theories are not necessarily contradictory. The capacity constraint theory could hold for the market as a whole (as a time series relationship), while the risky debt model could explain cross-sectional price differences among insurers at a given time (Weiss and Chung, 2004). Research on reinsurance prices using pooled data by Weiss and Chung (2004) provides support for both the capacity constraint and risky debt hypotheses. The risky debt hypothesis is not tested for in this study because only time series data are available.

${ }^{60}$ E.g., Cummins and Phillips (2000).

${ }^{61}$ A mid-term rate is used to allow for time to negotiate a claim amount if a loss occurs, especially for a partial loss. Also, losses caused by generic failures require several years to settle usually. See Space Insurance Briefing (2001). A negative sign is expected as well under an interest shock theory. 
Since premiums are a function of capacity available, capacity available is expected to be negatively related to past changes in loss ratios (i.e., the capacity available is expected to decrease as underwriting performance worsens). Thus the expected signs for the change in loss ratio variables are negative. The total launch failed percent variable is another underwriting variable that indicates the total number of failures that have accumulated since 1968 divided by the total number of launches since 1968. Capacity would be expected to be negatively related to higher failure ratios, so the coefficient for this variable is expected to be negative.

The minimum rate-on-line for satellite insurance is included in the regression. In general, the economics of supply and demand theory would imply a positive sign for this variable (i.e., a higher price leads to a greater supply). However, according to the capacity constraint hypothesis the expected sign for this variable is negative.

Overall conditions in the insurance industry may also play a role in determining coverage availability. If the insurance industry overall is flush with capital, then capacity for satellite insurance might be relatively high as insurers look for places to apply their capital. One indicator of total capacity commonly used in propertyliability insurance studies is the ratio of premiums written to surplus; higher values of this ratio are associated with tighter capital conditions in the insurance industry. Therefore a proxy for overall industry capacity might be the ratio of premiums written to surplus in the insurance industry for the insurers potentially available to write satellite insurance coverage (i.e., insurers capable of writing technical, unusual and complex coverages).

Thus the premiums written to surplus ratio of worldwide professional reinsurers might be useful as a measure of overall industry capacity. (In fact many satellite insurance writers are professional reinsurers. See Appendix B.) Unfortunately, this data is unavailable for the entire time period. However, premiums written to surplus for U.S. professional reinsurers are available for the time period. ${ }^{62}$ Therefore, premiums written to surplus for U.S. professional reinsurers are used to proxy for insurance industry conditions. ${ }^{63}$ Capacity is expected to be negatively related to real U.S. professional reinsurers' premiums written to surplus. ${ }^{64}$

62 Standard \& Poor's collects statistics on the top 100 reinsurers, but do not indicate the capital of the top 100 reinsurers prior to 1985 , and the definition of capital reported by Standard \& Poor's may have changed over the period 1985-2010. Therefore Standard \& Poor's data are not used in this study.

${ }^{63}$ The list of insurers writing satellite insurance includes many U.S. professional reinsurers. Furthermore, many foreign professional reinsurers have subsidiaries operating as separate professional reinsurers in the U.S. Hence capitalisation in the U.S. should be correlated with worldwide capitalisation.

${ }^{64}$ Some prior underwriting cycle studies use relative surplus (defined as surplus $t_{t} /$ average value of surplus from prior 5 years) as a measure of capacity (e.g., Winter, 1994). Augmented Dickey-Fuller tests indicated that this variable had a unit root (test statistic $=-1.471)$. Even when the first difference was taken, the Augmented Dickey-Fuller test statistic for this variable was -1.964 (vs. a 5 per cent critical value of -2.978), indicating that the first difference variable still had a unit root. 
168

New satellite value is included in the equation to reflect the fact that the values of satellites have changed dramatically over time as technology has changed. It is difficult a priori to determine the sign of this variable. If very large payload values are concentrated in single launches, then greater capacity would be needed to insure these. This would imply a positive sign for new satellite value. On the other hand, the large value at stake in a satellite launch may make insuring these less desirable by satellite insurance writers (i.e., a very large loss is possible in one event). In this case, the expected sign is negative.

Finally, a trend variable is included in the model to allow for underwriters' decisions about capacity to be adjusted by increased familiarity with this industry over time. There are no priors on the sign of this variable.

\section{Estimation of the regression equations}

Eqs. (3) and (4) are each tested individually for autocorrelation. Because some regressors may be endogenous, Durbin's alternative test for autocorrelation is used. ${ }^{65}$ Also, due to the relatively small number of observations, the small sample correction suggested by Davidson and MacKinnon ${ }^{66}$ is implemented. The results indicated that autocorrelation was not a problem in either equation. ${ }^{67}$

In Eqs. (3) and (4), the change in the rate and change in capacity variables appear both as dependent and independent variables in the set of equations. Therefore Eqs. (3) and (4) were estimated as a system of equations using 3SLS. The error term $\varepsilon_{t}$ is assumed to be $N\left(0, \sigma_{R}^{2}\right)$ and $v_{\mathrm{t}}$ is assumed to be $N\left(0, \sigma_{C}^{2}\right)$. The system of equations is iterated until the parameters converge. ${ }^{68}$

\section{Results}

Summary statistics for all variables used in the underwriting cycle analysis and hypothesis tests are reported in Table 1 . These results indicate that the average of the minimum rate-on-line is 0.1074 , while capacity averaged approximately $\$ 384$ million. The results of the test to determine whether underwriting cycles exist in satellite insurance, and estimation of cycle lengths (where appropriate) are presented in Table 2. The results of the regressions used for hypothesis testing are found in Table 3. This section discusses the main results.

\footnotetext{
65 Durbin (1970).

66 Davidson and MacKinnon (1993).

${ }^{67}$ For the satellite insurance rate equation, the $F$ statistic for first (second) order autocorrelation is 1.940 (0.944) with 1 and 30 ( 2 and 29) degrees of freedom. For the capacity equation, the $F$ statistic for first (second) order autocorrelation is 0.001 (0.177) with 1 and 30 (2 and 29) degrees of freedom.

${ }^{68}$ Greene (2003, pp. 405-407).
} 
Table 1 Summary statistic for regression variables

\begin{tabular}{|c|c|c|}
\hline Variable & Mean & Standard deviation \\
\hline Average rate & $\$ 0.1074$ & $\$ 0.044$ \\
\hline Minimum rate & $\$ 0.1300$ & $\$ 0.046$ \\
\hline Capacity $^{\mathrm{a}}$ & $\$ 384.0233$ & $\$ 360.675$ \\
\hline Loss ratio $_{1}$ & 0.8007 & 0.508 \\
\hline Loss ratio 2 & 0.8012 & 0.514 \\
\hline Loss atio $_{3}$ & 0.8013 & 0.520 \\
\hline Discount rate $(\%)$ & 6.8572 & 2.778 \\
\hline Number of launches & 99.6744 & 26.180 \\
\hline New satellite value $^{\mathrm{a}}$ & $\$ 115.9477$ & $\$ 47.0660$ \\
\hline Premiums written/surplus & 0.0364 & 0.596 \\
\hline Total launch failed $\%$ & 0.0659 & 0.028 \\
\hline$\Delta$ Average rate & $\$ 0.0001$ & $\$ 0.026$ \\
\hline$\Delta$ Minimum rate & $\$ 0.0008$ & $\$ 0.023$ \\
\hline$\Delta$ Capacity $^{\mathrm{a}}$ & $\$ 14.6250$ & $\$ 101.832$ \\
\hline$\Delta$ Loss ratio $_{1}$ & 0.0190 & 0.331 \\
\hline$\Delta$ Loss ratio $_{2}$ & 0.0200 & 0.335 \\
\hline$\Delta$ Loss ratio $_{3}$ & 0.0212 & 0.340 \\
\hline$\Delta$ Discount rate $(\%)$ & -0.0898 & 1.182 \\
\hline$\Delta$ Number of launches & -1.2857 & 12.887 \\
\hline$\Delta$ New satellite value ${ }^{a}$ & $\$ 2.9251$ & $\$ 37.171$ \\
\hline$\Delta$ Premiums written/surplus & -0.0221 & 0.173 \\
\hline$\Delta$ Total launch failed $\%$ & -0.0076 & 0.030 \\
\hline
\end{tabular}

ain millions USD.

Note: Minimum rate is the rate-on-line for the best risk and technology; Loss ratio is the ratio of claims to premiums with subscripts indicating lagged value; capacity is the sum of the maximum amounts each satellite underwriter is willing to provide for one launch; Number of launches is the total number of launches; New satellite value is the average value of a new satellite; Discount rate is the 5-year U.S. Treasury bond rate; Total launch failed \% is the total number of launch failures from 1969 to year $t-1$ divided by the total number of launches from 1969 to year $t-1$; Premiums written/surplus is the ratio of premiums written by professional U. S. reinsurers divided by the surplus of U.S. professional reinsurers. $\Delta X_{t}=X_{t}-X_{t-1}$.

\section{Underwriting cycle determination}

According to Table 2, underwriting cycles exist in the minimum rate-on-line, average rate-on-line and capacity. The cycle periods associated with the minimum and average rate-on-line are 12.48 and 13.95 , respectively, when a trend is included in the model. These periods are relatively long compared with the average 6-year cycle commonly cited in some studies. However, Lamm-Tennant and Weiss ${ }^{39}$ found cycle periods of 10 , 12 and 18 years in their study for some countries and lines, while Cummins and Outreville ${ }^{3}$ found cycle lengths as long as 11 years in their study. Chen et al. ${ }^{69}$ found a cycle length of approximately 14 years in some of their results. Perhaps the rather long

\footnotetext{
${ }^{69}$ Chen et al. (1999).
} 
Table 2 Results of tests for cycle existence for satellite insurance sample period 1968-2010

\begin{tabular}{|c|c|c|c|c|}
\hline \multirow[t]{2}{*}{ Variable } & \multicolumn{2}{|c|}{ Without trend ${ }^{\mathrm{a}}$} & \multicolumn{2}{|c|}{ With trend ${ }^{\mathrm{b}}$} \\
\hline & Cycle & Period & Cycle & Period \\
\hline Loss ratio & No & NA & No & NA \\
\hline Minimum rate & Yes & 13.41 & Yes & 12.48 \\
\hline Average rate & No & NA & Yes & 24.94 \\
\hline Capacity & Yes & 43.94 & Yes & 13.95 \\
\hline
\end{tabular}

${ }^{\text {a }}$ The OLS equation estimated is $V_{t}=a+a_{1} V t-1+a_{2} V_{t-2}+e_{t}$.

${ }^{\mathrm{b}}$ The OLS equation estimated is $V_{t}=a+a_{1} V t-1+a_{2} V_{t-2}+a_{3}$ Trend $+e_{t}$.

NA - not available - a cycle does not exist

The cycle period is estimated as $T=2 \pi /\left(\cos ^{-1}\left(\sqrt[2]{a_{1}}-a_{2}\right)\right)$.

Note: Capacity is defined as the sum of the maximum dollar amount of insurance that each underwriter is willing to provide for an individual risk.

cycle periods in this line for rates and capacity are related to the lack of homogeneous data on which to base satellite insurance rates. Recall that this line does not benefit from the law of large numbers relative to most other insurance lines with respect to homogeneity of data. Hence data for several periods as well as considerable judgment may enter the rating process leading to a longer cycle period. ${ }^{70}$

Surprisingly, no cycle is detected in the loss ratio. The reason for this is not clear. Perhaps the explanation lies in the difference in cycle periods for capacity and rateson-line. That is, rates-on-line do not appear to be quite in phase with the phase for capacity. In fact the phase for capacity when a trend is not included in the model is unrealistically long, given the length of the time series.

The results in Figure 5 provide additional information on phases. This figure indicates that rates and capacity for launch insurance tend to mirror each other (although not perfectly). Hence when the minimum rate-on-line is at its peak, capacity is near its trough, and the cycles are not in phase. These results might occur if there are important factors affecting capacity that do not affect rates. For example, these variables might be out of phase if rates are based on past losses primarily, while capacity is determined largely from overall insurance industry conditions. The capacity constraint theory also predicts an out of phase result, since capacity is hypothesized to be inversely related to rates. Recall that premiums are a function of the rate-on-line and the amount of coverage available. If the latter two are out of phase, then the time series

${ }^{70}$ Tests for cycles and cycle period determination were conducted for a subsample of our time series, 1984-2010. During this period, the satellite insurance industry is considered to be more fully developed. The results of the analysis are similar to what is reported here except the cycle periods appear to be shorter. For example, the minimum (average) rate on line has a cycle length of 10.38 (10.07) when a trend is included in the model. 
behaviour associated with cycles may not be observable from data based on premiums and losses. An alternative explanation is that paid losses rather than incurred losses are used to determine the loss ratio, and this is affecting the results.

\section{Results from hypothesis testing}

Table 3 contains results for testing the hypotheses. The hypotheses primarily centre on the rational expectations/institutional intervention hypothesis and the capacity

Table 3 OLS and three-stage least squares (3SLS) regression results sample period 1972-2010

\begin{tabular}{|c|c|c|c|c|}
\hline \multirow[t]{2}{*}{ Independent variables } & \multicolumn{2}{|c|}{$O L S$} & \multicolumn{2}{|c|}{$3 S L S$} \\
\hline & Coefficient & $t$-statistic & Coefficient & $z$-statistic \\
\hline \multicolumn{5}{|l|}{ Price equation } \\
\hline \multicolumn{5}{|c|}{ Dependent variable: $\Delta$ Minimum rate } \\
\hline Intercept & 0.0136 & $2.24 * *$ & 0.0131 & $1.94 *$ \\
\hline$\Delta$ Loss ratio $_{1}$ & 0.0210 & $2.55 * *$ & 0.0207 & $2.40^{* *}$ \\
\hline$\Delta$ Loss ratio 2 & 0.0145 & $1.93 *$ & 0.0146 & 1.47 \\
\hline$\Delta$ Loss ratio $_{3}$ & 0.0020 & 0.82 & 0.0017 & 0.19 \\
\hline$\Delta$ Capacity & -0.0002 & $-6.10 * * *$ & -0.0002 & $-2.56 * * *$ \\
\hline$\Delta$ Discount rate & -0.0089 & $-2.64 * *$ & -0.0088 & $-3.05 * * *$ \\
\hline$\Delta$ Number of launches & 0.0003 & 1.46 & 0.0002 & 1.11 \\
\hline Trend & -0.0005 & $-2.09 * *$ & -0.0049 & $-2.02 * *$ \\
\hline$R$-squared & 0.5959 & & 0.5936 & \\
\hline \multicolumn{5}{|l|}{ Capacity equation } \\
\hline \multicolumn{5}{|l|}{ Dependent variable: $\Delta$ Capacity } \\
\hline Intercept & 60.7518 & $2.45 * *$ & 56.4501 & $1.97 * *$ \\
\hline$\Delta$ Loss ratio $_{1}$ & 29.9209 & 1.02 & 14.5592 & 0.36 \\
\hline$\Delta$ Loss ratio 2 & -36.5516 & -1.31 & -42.5592 & -1.06 \\
\hline$\Delta$ Loss ratio 3 & -6.8148 & -0.18 & -2.7315 & -0.07 \\
\hline$\Delta$ Minimum rate & -2694.3980 & -4.99 & -1879.5990 & -1.75 \\
\hline$\Delta$ Premiums written/surplus & -117.5363 & -1.65 & -148.9381 & $-1.95^{*}$ \\
\hline$\Delta$ New satellite value & -0.7215 & $-1.79 *$ & -0.7276 & $-2.39 * *$ \\
\hline$\Delta$ Total launch failed $\%$ & 299.3906 & 0.66 & 210.3427 & 0.54 \\
\hline Trend & -1.8912 & $-1.77 *$ & -1.7479 & -1.62 \\
\hline$R$-squared & 0.5786 & & 0.5411 & \\
\hline
\end{tabular}

*** Significant at the 1 per cent level; ** Significant at the 5 per cent level; * Significant at the 10 per cent level.

Note: Minimum rate is the rate-on-line for the best risk and technology; Loss ratio is the ratio of claims to premiums with subscripts indicating lagged value; capacity is the sum of the maximum amounts each satellite underwriter is willing to provide for one launch; Number of launches is the total number of launches; New satellite value is the average value of a new satellite; Discount rate is the 5-year U.S. Treasury bond rate; Total launch failed \% is the total number of launch failures from 1969 to year $t-1$ divided by the total number of launches from 1969 to year $t-1$; Premiums written/surplus is the ratio of premiums written by professional U. S. reinsurers divided by the surplus of U.S. professional reinsurers. $\Delta X_{t}=X_{t}-X_{t-1}$. 
constraint hypothesis. The main variables of interest for the hypotheses are the coefficients for the changes in the minimum rate-on-line, changes in lagged loss ratios and changes in capacity. The remainder of this section discusses these results in more detail.

According to Hypothesis 1a, the minimum rate-on-line should be positively and significantly related to lagged past losses. In both the OLS and 3SLS results for the rate-on-line equation, the coefficients for changes in the lagged loss ratios are positive, and the coefficients for two of these are significant in the OLS results. In the 3SLS results, the coefficient for the change in the first lagged loss ratio is significant while the coefficient for the second lagged loss ratio is positive with a $t$-statistic of approximately 1.5. In both the OLS and 3SLS results, the coefficients decline directly with the number of lags, as expected. ${ }^{71}$ Thus Hypothesis $1 \mathrm{a}$ is partly supported.

Hypothesis $1 \mathrm{~b}$ posits that capacity (i.e., the maximum amount of coverage available for launch insurance) should be negatively related to past losses. The results for the capacity equation in Table 3 do not support this hypothesis. That is the coefficients for changes in the lagged loss ratios are not significant in the OLS or 3SLS results, although four of the six coefficients do have a negative sign. Thus past losses do not appear to be significantly related to capacity, contradicting Hypothesis $1 b$.

The coefficient for the change in capacity is negative and significant in the rateon-line equation and the change in the minimum rate is negative and significant in the capacity equation. This result supports the capacity constraint hypothesis stated in Hypothesis 2. The fact that both variables are significant in the 3SLS results indicate that average rates and capacity are determined simultaneously. This result supports Hypothesis $3 .^{72,73}$

71 That is, the lagged loss ratio from three periods ago has a lesser impact (smaller coefficient) than the second or most recent lagged loss ratio. And the coefficient for the second lagged loss ratio is smaller than for the most recent lagged loss ratio.

72 As a robustness check, the same regression analysis was conducted using the change in the real average rate-on-line in place of the change in the real minimum rate. The results for these models are similar. Changes in the real average rate are positively related to changes in all of the lagged loss ratios in the three-stage-least-squares results, and the coefficient of the first lagged loss ratio is significant. Change in the real average rate is negatively and significantly related to change in capacity in the capacity equation. In the average rate equation, the change in capacity is negatively related to the change in the average rate but the coefficient is not significant ( $t$-stat is -1.38$)$. Thus, overall, the results are similar across the two sets of models, but the results using the change in the minimum rate are stronger.

73 As another robustness test, the regressions are run using a period of time when the satellite insurance market is considered to be more fully developed, 1984-2010. The results remain the same. However, not all of the variables pass the unit root test (specifically, the change in the loss ratios). Thus we do not report these results. 


\section{Other regression results}

Changes in capacity appear to be significantly related to changes in overall insurance industry conditions in the 3SLS results. That is, change in premiums written/surplus has a negative and significant coefficient in the 3SLS results in Table 3. Recall that as the premiums written/surplus increases, overall industry capacity decreases. Thus the results suggest that as overall industry conditions tighten (premiums written/surplus goes up), less capacity is available for satellite insurance.

The change in satellite value is negative and significant in the capacity equation in both the OLS and 3SLS results. Thus as the value of satellites increases, less capacity appears to be devoted to the industry, perhaps because of the risk of a large loss from one event. The trend variable in the capacity equation is negative in both equations, but significant at the 10 per cent level in the OLS results only. Thus there is very limited evidence of a trend in capacity in this industry over time. Finally, the total launch failed percent is insignificant in the capacity equation.

With respect to the regression control variables in the minimum rate-on-line regression, the change in the minimum rate-on-line is negatively related to the change in the discount rate as expected. The results also indicate that there is a general downward trend in the change in the minimum rate for the satellite industry since the coefficient for trend in the change in minimum rate-on-line equation is negative and significant. The change in the total number of launches is insignificant in the price equation.

\section{Conclusion}

This study uses a unique, unpublished data set that covers the inception of the satellite insurance industry to the present to investigate underwriting cycles. The main objectives are to determine whether an underwriting cycle is present, and to determine the length and causes of the underwriting cycle if it exists. In the course of doing this, the rational expectations/ institutional intervention and capacity constraint hypotheses are tested. Two factors important in determining premium (the rate-on-line and the amount of coverage available in the industry) are analysed, and this is the first research to conduct underwriting cycle analysis on each component individually. The results largely confirm the existence of an underwriting cycle in the satellite insurance market because underwriting cycles are found in the minimum rate-on-line, average rate-online and capacity. The corresponding cycle periods are relatively long (13-25 years) compared with the average 6-year cycle commonly cited in other studies. No underwriting cycle is found in the loss ratio, unlike other studies.

The analysis of changes in the minimum rate-on-line provides some support for the rational expectations/institutional intervention hypothesis because a positive and significant relationship between the minimum-rate-on line and lagged loss ratios is 
found. Conversely, capacity, measured as the sum of the maximum limits available on one risk from industry underwriters for launch insurance, is not significantly related to lagged loss ratios. Instead, maximum coverage available in the satellite insurance industry is more significantly related to capitalisation in the worldwide insurance industry and changes in the value of a new satellite.

Because of the unique data used in this study, we are able to determine that the maximum coverage available for a new launch in the satellite insurance industry and the rate-on-line are determined simultaneously. The minimum rate-on-line is negatively related to capacity (coverage availability), as predicted by the capacity constraint theory. No previous study has been able to undertake this sort of analysis.

By analysing coverage availability and rates-on-line, this research makes an important contribution to understanding the determinants of premium changes during the operation of the underwriting cycle. It is especially interesting that no cycle in the loss ratio is found, but cycles in satellite insurance industry capacity and rates-on-line exist. This result suggests that cycles may still exist in other lines of insurance even when no cycle appears to be present in the loss ratio. The lack of an apparent cycle may be related to whether rates-on-line are in phase with capacity.

Further, this research is important because the satellite insurance industry helps to support the satellite industry itself. Satellites provide global communications, meteorological analysis, GPS, and military and scientific needs. Without satellite insurance, it might be impossible to obtain financing for purchases and launches of satellites.

\section{References}

2005 State of the Satellite Industry Report. (2006) Satellite Industry Association, from www.sia.org/stateof-the-satellite-industry-report/, accessed 2 March 2012.

2010 State of the Satellite Industry Report. (2011) Satellite Industry Association, from www.sia.org/stateof-the-satellite-industry-report/, accessed 2 March 2012.

Bannister, J. (1992) Breaking even the final frontier. Lloyd's List, 9 November 1992.

Berry-Stolzle, T. and Born, P. (2012) 'The effect of regulation on insurance pricing: The case of Germany', The Journal of Risk and Insurance 79(1): 129-164.

Browne, M.J. and Hoyt, R.E. (1992) 'Excess returns and the underwriting cycle in the property-liability insurance market', Journal of Insurance Regulation 11(1): 67-78.

Chen, R., Wong, K. and Lee, H.C. (1999) Underwriting cycles in Asia, Journal of Risk and Insurance 66(1): 29-47.

Choi, S., Hardigree, D. and Thistle, P.D. (2002) The property/liability insurance cycle: A comparison of alternative models, Southern Economics Journal 68(3): 530-548.

Cummins, J.D. and Danzon, P. (1997) Price, financial quality, and capital flows in insurance markets, Journal of Financial Intermediation 6(1): 3-38.

Cummins, J.D. and Outreville, F. (1987) An international analysis of underwriting cycles, The Journal of Risk and Insurance 54(2): 246-262.

Cummins, J.D. and Phillips, R.D. (2000) Applications of financial pricing models in property-liability insurance, in G. Dionne, (ed.) Handbook of Insurance, Boston: Kluwer Academic Publishers. 
d'Angelo, G. (1994) Aerospace Business Law, Westport: Quorum Books.

Davidson, R. and MacKinnon, J.G. (1993) Estimation and Inference in Econometrics, New York: Oxford University Press.

Dickey, D.A. and Fuller, W.A. (1979) Distribution of the estimators for autoregressive time series with a unit root, Journal of the American Statistical Association 74(366a): 427-431.

Doherty, N. (1989) Risk-bearings contracts for space enterprises, The Journal of Risk and Insurance 56(3): 397-414.

Doherty, N. and Kang, H. (1988) Interest rates and insurance price cycles, Journal of Banking and Finance 12(2): 199-214.

Durbin, J. (1970) Testing for serial correlation in least-squares regressions when some of the regressors are lagged dependent variables, Econometrica 38(3): 410-421.

Fabre, H. (2002) Insurance strategies for covering risks in outer space: A French perspective, Space Policy 18(4): 281-6.

Federal Aviation Administration (FAA). (2010) Commercial Space Transportation: Year In Review. Washington: Federal Aviation Administration (FAA).

Gobbo, G. (1991) An insurer's view of the space business, Space Policy 7(1): 46-50.

Grace, M. and Hotchkiss, J. (1995) External impacts on the property-liability insurance cycle, The Journal of Risk and Insurance 62(4): 738-754.

Greene, W.H. (2003) Econometric Analysis, 5th edn, Upper Saddle River, NJ: Prentice-Hall.

Gron, A. (1994) Capacity constraints and cycles in property-casualty insurance markets, RAND Journal of Economics 25(1): 110-127.

Harrington, S.E. and Danzon, P.M. (2000) The economics of liability insurance, in G. Dionne, (ed.), Handbook of Insurance, Boston: Kluwer Academic Publishers.

Harrington, S.E., Danzon, P.M. and Epstein, A.J. (2008) "Crises" in medical malpractice insurance: Evidence of excessive price-cutting in the preceding soft market, Journal of Banking and Finance 32(1): 157-169.

Harrington, S.E. and Niehaus, G. (2000) Volatility and underwriting cycles, in G. Dionne, (ed.) Handbook of Insurance, Boston: Kluwer Academic Publishers.

Hollings, E. (1988) Insurance and the U.S. Commercial Space Launch Industry, Committee on Commerce, Science and Transportation-U.S. Senate, Washington, U.S. Government Printing Office [Report No 86-822 O].

Hughes, B. (1984) How Does Private Enterprise Insure the \$200 Million Space Venture? Paper presented at American Bar Association, Forum Committee on Air \& Space Law, Orlando, 24 February 1984.

Johansen, S. (1995) Likelihood-Based Inference in Cointegrated Vector Auto-Regressive Models, Oxford: Oxford University Press.

Kunstadter, C. (2005) Space Insurance Experience and Outlook: A Statistical Review of Volatility, Proceedings from 13th International Space Insurance Conference 2005.

Kunstadter, C. (2007) Space Insurance Overview, Proceedings from 14th International Space Insurance Conference 2007.

Kunstadter, C. (2009) A Statistical Review of Space Insurance, Proceedings from 15th International Space Insurance Conference 2009.

Kunstadter, C. (2011) Space Insurance Update, Proceedings from 16th International Space Insurance Conference 2011.

Kunstadter, C. (2012) View from the Leading Edge, Proceedings from 2nd World Space Risk Forum 2012.

Lai, G.C, Witt, R.C., Fung, H.G., Macminn, R.D. and Brockett, P.L. (2000) Great (and not so great) expectations: And endogenous economic explication of insurance cycles and liability crises, The Journal of Risk and Insurance 75(4): 617-652.

Lamm-Tennant, J. and Weiss, M.A. (1997) International insurance cycles: Rational expectations/ institutional intervention, The Journal of Risk and Insurance 64(3): 415-439.

Lys, P.-E. (1999) The final frontier-Insuring risks in space, Global Risk Report 2: 9-13. 
Manikowski, P. (2004) The satellite insurance market as a part of the insurance market, Argumenta Oeconomica 16(2): 139-151.

Manikowski, P. (2005a) Is there a special market for satellite insurance? Foundations of Control and Management Sciences 4: 63-71.

Manikowski, P. (2005b) The Columbia Space shuttle tragedy: Third-party liability implications for the insurance of space losses, Risk Management and Insurance Review 8(1): 141-150.

Manikowski, P. (2013) Wskaźniki empiryczne w analizie cykli ubezpieczeniowych [eng.: Empirical indices in the underwriting cycles analysis], Ekonomista 3: 33-409.

Margo, R. (2000) Aviation Insurance. The Law and Practice of Aviation Insurance, Including Hovercraft and Spacecraft Insurance, 3rd edn, London, Edinburgh, Dublin: Butterworths.

Market Review. (various years) London: International Space Brokers.

Meredith, P. (2008) Space insurance law-With a special focus on satellite launnch and in-orbit policies, The Air \& Space Lawyer 21(4): 13-5.

Nielsen, B. (2001) Order determination in general vector autoregressions, Working Paper, Department of Economics, University of Oxford and Nuffield College.

NSTAC. (2004) NSTAC Satellite Task Force Report to the President, Washington D.C.

Pindyck, R.S. and Rubinfeld, D.L. (1998) Properties of Stochastic Time Series, Econometric Models and Economic Forecasts, 4th edn, New York: McGraw-Hill, Chapter 16, pp. 507-519.

Quarterly Launch Report. (2002) United States Department of Transportation, Federal Aviation Administration, Fourth Quarter 2002.

Satellite Insurance Market Overview. (various years) London: Willis Inspace.

Schöffski, O. and Wegener, A. (1999) Risk management and insurance solutions for space and satellite projects, The Geneva Papers on Risk and Insurance-Issues and Practice 24(2): 203-215.

Smith, M. and Gahin, S. (1983) The underwriting cycle in property and liability insurance (1950-1978), Proceedings from Risk Theory Seminar, Helsinki, Finland.

Space Insurance Briefing. (2001) London: Marsh Space Projects Ltd.

Space Insurance Market Report. (2010) AON Risk Services-ISB.

Space Risks_Pocket Guide to Space and Space Insurance. (1995) London: Willis Corroon Inspace.

Space Risks III-Pocket Guide to Space Insurance and the Satellite Frequency Spectrum. (1997) London: Willis Corroon Inspace.

Stahler, W. (2003) Of new risks, unknown risks and uncertainty, Risk Management 33: 1-4.

Todd, D. (2006) 2005 Space Year in Review, from www.airclaims.co.uk, accessed 12 December 2006.

Venezian, E. (1985) Ratemaking methods and profit cycles in property and liability insurance, The Journal of Risk and Insurance 52(3): 477-500.

Wade, D. and Gubby, R. (2004) A review of recent developments in the global space insurance market, 55th International Astronautical Congress 2004; Vancouver, Canada, IAC-04-IAA.4.9.1.01.

Wegener, A. and Schöffski, O. (1997) Risk Management und Versicherungskonzepte für Raumfahrt- und Satellitenprojekte, Versicherungswirtschaft 52(10): 688-694.

Weiss, M.A. and Chung, J.H. (2004) U.S. reinsurance prices, financial quality, and global capacity, The Journal of Risk and Insurance 71(3): 437-467.

Williamson, M. (1990a) Dictionary of Space Technology, Bristol and New York: Adam Hilger.

Williamson, M. (1990b) The Communications Satellite, Bristol and New York: Adam Hilger.

Winter, R. (1994) The dynamics of competitive insurance markets, Journal of Financial Intermediation 3(4): 379-415.

Zocher, H. (1988a) Neuere internationale Entwicklungen in der Raumfahrt und ihrer Versicherung (II), Versicherungswirtschaft 43(2): 147-55.

Zocher, H. (1988b) Neuere internationale Entwicklungen in der Raumfahrt und ihrer Versicherung (III), Versicherungswirtschaft 43(3): 212-8. 


\section{Appendix A}

\section{Types of satellite insurance policies}

Various types of satellite insurance policies have been developed through the collaborative work of aerospace clients, brokers and insurance underwriters. The goal was to develop flexible forms of insurance for this volatile class of exposure. ${ }^{74}$ Over time and with increasing experience, the insurance market has continued to offer better scope of insurance cover. Currently there are two basic types of satellite insurance: property insurance (including pre-launch, launch and in-orbit insurance) and third-party liability insurance, and these are described in this appendix. ${ }^{75}$

\section{Property insurance for pre-launch, launch and in-orbit damages}

Property insurance is available to cover particular phases of the satellite project: manufacturing and pre-launch activities, launch into space, and in-orbit life. ${ }^{76}$ Pre-launch insurance covers against physical loss or damage of the asset during the pre-launch period (i.e., during transportation, temporary storage in the launch area, integration with the launcher, the configuration of the satellite, ${ }^{77}$ as well as other preparations for launch, including the potentially dangerous loading of fuel). This coverage usually attaches after offloading the satellite and the launch vehicle at the insurance location (e.g. the launch platform) and terminates at "intentional ignition". Coverage is usually placed in the London marine and cargo insurance market. ${ }^{78}$

Although launch insurance originally was limited to the actual launch phase, coverage now extends for a considerable period of initial satellite operation. ${ }^{79}$ The policy provides coverage for losses arising out of the launch process and during early orbit operations such as during transfer into orbit and initial deployments. Coverage then continues throughout in-orbit acceptance to the end of the policy period. Usually the minimum coverage period is at least 180 days following the launch for

74 d'Angelo (1994).

${ }^{75} \mathrm{We}$ are describing only the most typical coverage; however, there are several variations of it (e.g., satellite launch vehicle flight only insurance, satellite post separation insurance, etc.), as well as some other (less frequently used) types of space policies (e.g., launch risk guarantee, satellite loss of revenue insurance, etc.) (see Schöffski and Wegener, 1999; Meredith, 2008).

${ }^{76}$ Meredith (2008).

${ }^{77}$ Configuration of the satellite may include parameters such as nodal period, inclination of the orbit, apogee and perigee. The nodal period is the time period between two successive northbound crossings of the equator (usually in minutes). With respect to inclination of the orbit, a polar orbit is 90 degrees and an equatorial orbit is 0 degrees. The apogee is the highest altitude above the Earth's surface (in kilometers) and the perigee is the lowest altitude.

${ }^{78}$ Williamson (1990b).

79 The definition of the "launch" varies from contract to contract, but attachment of risk typically occurs at intentional ignition of the launcher's main engines, the opening of the launch table restraints, or at lift-off. 
geostationary orbit spacecraft to ensure that the spacecraft has experienced a full season of solar eclipses in its orbit. Coverage usually includes payment for the proportion of satellite capability lost as a result of failure, with provisions made for loss of payload function and loss of service life due to premature consumption of propellants or excessive degradation of the solar array power. Coverage for payload losses is usually for an agreed upon amount for each transponder. Coverage for "satellite loss of lifetime" is based on estimates of the remaining life after the loss of fuel or power giving rise to the claim. ${ }^{80}$ Satellites that are not transponder based, such as geo-mobile or imaging systems, have loss formulas based on their performance specifications and commercial operations requirements. ${ }^{81}$

In-orbit insurance, also known as "life" insurance, covers proper functioning of the satellite during its operational lifetime, usually in yearly renewable phases. It usually commences from the expiration of the launch policy. Coverage is, however, subject to a review of the satellite health status prior to commencement of coverage for each policy period. If anomalies occur, exclusions may be introduced by insurers, or by the buyer, in order to maintain coverage for the remainder of the satellite's life at reasonable cost. ${ }^{82}$

\section{Third-party liability insurance}

Space third-party liability insurance covers the legal liability arising from damage to third parties during the preparations for launch, the lift-off itself, in-orbit operations of a satellite program and, finally, re-entry. Compensation is provided in the event of personal injury and property damage to third parties, both on the ground and in space, caused by the launch vehicle or the satellite. Thus damages such as the following are covered by third-party liability insurance: damages occurring when a satellite, a rocket or its components fall to the ground; damages from fire during ignition; damages from an explosion of a satellite in orbit; and damage from collision of the satellite with another spacecraft. ${ }^{15}$

\footnotetext{
${ }^{80}$ In all cases where there is a loss of both fuel and power, careful evaluation is required to avoid double recovery of the loss.

${ }^{81}$ Margo (2000).

${ }^{82}$ Wegener and Schöffski (1997).
} 


\section{Appendix B}

Table B1 List of reinsurers underwriting satellite insurance

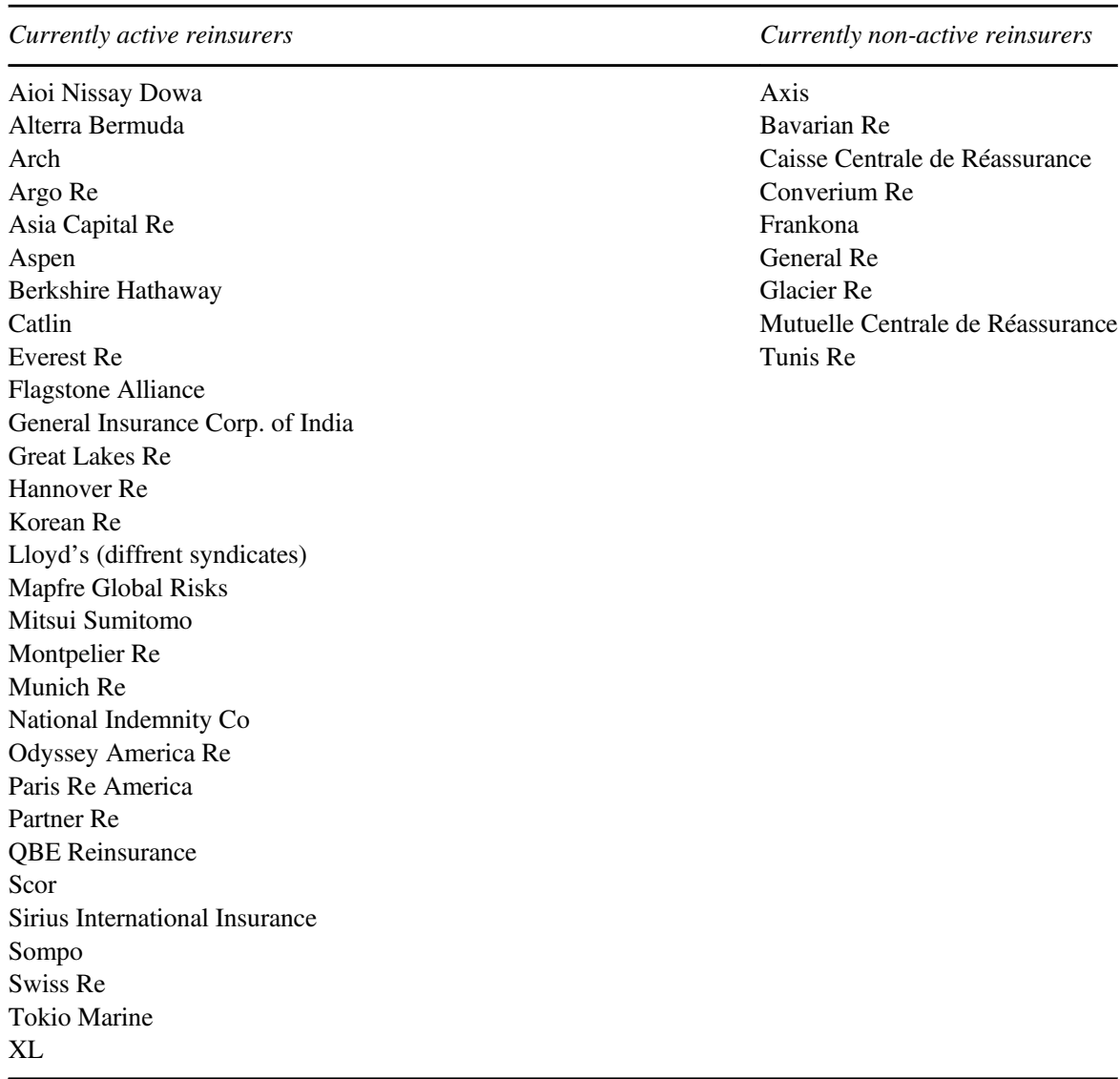

This list includes reinsurers underwriting satellite insurance directly or indirectly (as members of pools). 


\section{Appendix C}

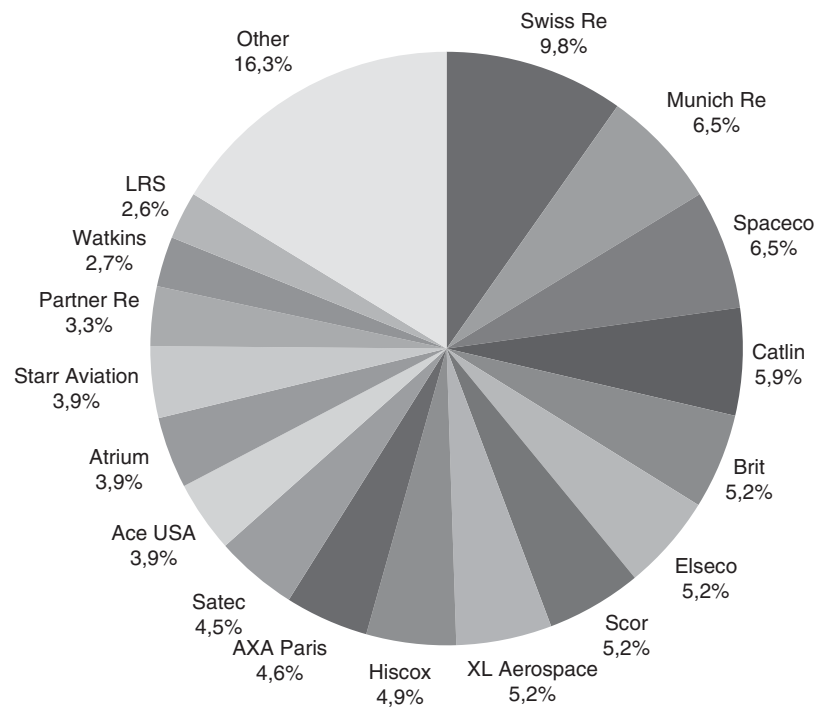

Figure C1. Market share information for the year 2010 (measured by capacity). Source: Space Insurance Market Report (2010). 


\section{Appendix D}

Table D1 Results of unit root and cointegration tests

\begin{tabular}{|c|c|c|c|}
\hline \multicolumn{4}{|c|}{ Augmented Dickey-Fuller unit root tests } \\
\hline Series & Test statistic & Difference in series & Test statistic \\
\hline Capacity & $-2.832 *$ & $\Delta$ Capacity & $-3.325^{* *}$ \\
\hline Minimum rate & -2.619 & $\Delta$ Minimum rate & $-3.145^{* *}$ \\
\hline Discount rate & -2.158 & $\Delta$ Discount rate & $-6.304 * * *$ \\
\hline New satellite value & $-2.885^{*}$ & $\Delta$ New satellite value & $-4.986 * * *$ \\
\hline Premiums written/surplus & -2.072 & $\Delta$ Loss ratio $(\operatorname{lag} 1)$ & $-4.460 * * *$ \\
\hline Loss ratio (lag 1) & $-2.802 *$ & $\Delta$ Premiums written/surplus & $-8.012 * * *$ \\
\hline Loss ratio (lag 2) & $-2.739 *$ & $\Delta$ Loss ratio (lag 2) & $-13.752 * * *$ \\
\hline Loss ratio (lag 3) & -1.395 & $\Delta$ Loss ratio (lag 3 ) & $-4.513 * * *$ \\
\hline Number of launches & -1.513 & $\Delta$ Number of launches & $-4.566 * * *$ \\
\hline Total launch failed $\%$ & -2.175 & $\Delta$ Total launch failed $\%$ & $-5.827 * * *$ \\
\hline \multicolumn{4}{|c|}{ Results of cointegration tests } \\
\hline Series 1 & Series 2 & Lags & Johansen test statistic \\
\hline Minimum rate & Number of launches & 2 & 12.2452 \\
\hline Minimum rate & Capacity & 2 & $17.417 * *$ \\
\hline Minimum rate & Discount rate & 4 & 14.101 \\
\hline Minimum rate & Loss ratio (lag 1) & 2 & 15.331 \\
\hline Minimum rate & Loss ratio (lag 2) & 2 & $28.162 * * *$ \\
\hline Minimum rate & Loss ratio (lag 3) & 4 & $25.977 * * *$ \\
\hline Capacity & Average new satellite value & 2 & $18.8157 * *$ \\
\hline Capacity & Premiums written/surplus & 2 & 10.510 \\
\hline Capacity & Total launch failed $\%$ & 3 & 14.356 \\
\hline Capacity & Loss ratio (lag 1) & 2 & 8.5017 \\
\hline Capacity & Loss ratio (lag 2) & 2 & 8.0298 \\
\hline Capacity & Loss ratio (lag 3) & 2 & 7.7089 \\
\hline
\end{tabular}

*** Significant at the 1 per cent level; ** Significant at the 5 per cent level; * Significant at the 10 per cent level.

Note: number of lags determined using Nielsen (2001). Test based on Johansen (1995).

\section{About the Authors}

Piotr Manikowski obtained his $\mathrm{PhD}$ in Economics from the Poznań University of Economics in 2003 and has since been working in the Insurance Department at Poznań University of Economics, Poland. His research has focused on satellite insurance and underwriting cycles. 
Mary A. Weiss, PhD, is Deaver Professor of Risk, Insurance and Healthcare Management at the Fox School of Business at Temple University, U.S.A. She is a Past President of the American Risk and Insurance Association (ARIA), as well as the Editor of Risk Management and Insurance Review and a co-Editor for the Journal of Risk and Insurance. She served as a Distinguished Scholar at the NAIC's Center for Insurance Policy \& Research, a think-tank, in 2009-2010. Her research has focused on financial services conglomeration, efficiency measurement of insurers, no-fault automobile insurance, reinsurance, regulation and underwriting cycles. 